\title{
LA PROMESA DEL ARTE. EL ARTISTA COMO EDUCADOR DE IDENTIDADES COLECTIVAS
}

\author{
The promise of art. The artist as an educator of collective identities
}

\begin{abstract}
Amalia Barboza'
\section{Resumen}

En el presente artículo, me propongo analizar algunos escritos sobre el arte de Georg Simmel, en donde la expresión artística es vista como canalización de identidades y emociones colectivas. Simmel ve en el arte un instrumento de expresión de emociones individuales que, al ser acogidas por el público, se transforman en identidades colectivas. El arte parece entonces poder cumplir la promesa de establecer puentes de entendimiento. Simmel prestó atención a esta promesa del arte y estableció un diálogo con diferentes expresiones artísticas, desde la música y la escultura hasta la pintura.
\end{abstract}

Palabras-chave: Georg Simmel; Arte; Identidades Colectivas.

\begin{abstract}
In the present article, I propose to analyze some writing by Georg Simmel, in which artistic expression is seen as a well to emerge collective identities and emotions. Simmel sees art as an instrument for the expression of collective emotion that, once they are received by the public, become collective identities. Art thus seem then to be able to fulfill the promise of establishing bridges of understanding. Simmel payed close attention to the promise of art and he has established a dialogue with different artistic expressions, from music and sculpture to painting.
\end{abstract}

Key-words: Georg Simmel; Art; Collective Identities.

\footnotetext{
1 Professora de Teoria e Método das Ciências Culturais, Universidade de Sarre, Saarbrücken, Alemanha. Email: a.barboza@mx.uni-saarland.de.
} 
Ihr seid nur Brücken: mögen Hohere auf euch hinüber schreiten! Vosotros solo sois puentes: ¡Que se haga posible que desde vosotros surja lo elevado! (Also sprach Zarathustra, Friedrich Nietzsche)

\author{
Misteriosamente \\ O Badauê surgiu \\ Sua expressão cultural \\ O povo aplaudiu \\ (Badauê, Caetano Veloso)
}

En la canción de Caetano Veloso "Badauê" se resalta, con instrumentos y palmas de fondo, el fenómeno de que una expresión cultural como el Badauê, fiesta, música y baile a la vez, surja de alguna forma misteriosa y sea inmediatamente aplaudida por el pueblo. El pueblo no solo aplaude el surgimiento del Badauê, sino que a la vez se mueve siguiendo su ritmo, llevándolo de esta forma a la práctica y transformándolo en una expresión cultural compartida por un grupo de personas, llegando incluso a transformarse en una suerte de forma de vida comunitaria ¿Pero de donde surge el Badauê? El Badauê no es autoría de Caetano Veloso. El Badauê es una expresión que surge del pueblo del norte de Brasil, una expresión anónima y grupal. El cantor y compositor Caetano Veloso sabe apropiarse de esa expresión cultural y cantar a un pueblo, que, sin ser consciente, es él mismo quien ha creado una expresión colectiva. El pueblo es el autor del Badauê y se aplaude, sin saberlo, a sí mismo. Y la música de Caetano sirve en este caso como una reflexión y un elogio a la creatividad anónima.

Esta canción dedicada al Badauê nos hace ver cómo una expresión cultural artística funciona como medio de expresión de un pueblo, logrando establecer un lazo comunitario y una identidad grupal. Cabe destacar que no sólo las expresiones colectivas tienen esta función, sino que también las creaciones artísticas de autoría individual pueden llegar a ser aplaudidas por el pueblo. El artista se transforma entonces en una especie de puente, parafraseando la cita de Nietzsche, que a través de su creación artística atrae al público a una esfera elevada, la esfera del arte. En los comentarios que aparecen debajo de las canciones de Caetano Veloso, publicadas en YouTube, nos podemos dar una idea de esta función que se le otorga al artista. Tomemos por ejemplo el siguiente comentario: "Um Caetano só nasce 
uma vez no mundo, pois o universo fica com a boca aberta prolongadamente $e$ esquece do seu trabalho..." (Alex Dornelli) ${ }^{2}$.

Este comentario resalta el papel del artista, al que se le atribuye la autoría de una obra y a la vez la función de que, a través de su arte, deja a su público "con la boca abierta prolongadamente olvidándose de su trabajo". Es como si el artista llevase al público a una esfera elevada en donde todo lo cotidiano queda olvidado. A su vez, la expresión “con la boca abierta” nos hace ver que aparentemente esta elevación no tiene un objetivo claro. La pregunta que nos podemos hacer es si la función del arte es la de sorprender (dejando con la boca abierta) o si tiene otra función social, una dirección concreta u otro objetivo más allá del dejar al público sorprendido ¿Cuál es la función del arte? ¿Qué papel juega el artista? Y ¿qué relación se da entre el artista, el arte y su público, una vez que este es “atrapado" o "sorprendido" por la expresión cultural?

La función del arte de saber atraer al público, como una especie de imán, ha sido objeto de estudio de la sociología. Podríamos decir que esta función es central para las ciencias sociales, siendo el significado sociológico por excelencia: el arte visto no como acto de producción de los artistas, sino que como acto social de establecer un puente de entendimiento entre el productor y el receptor. También Georg Simmel dedico atención, en su sociología, a la capacidad del arte en su función de crear un sistema estético y emocional que atrae a varias personas a su campo de radiación. Por ejemplo, en un capítulo de su libro Sociología. Estudios sobre las formas de socialización, en el que Simmel trata la función de las joyas y la decoración. La esencia y sentido de las joyas es, para Simmel, la de atraer los ojos de los otros hacia las personas que las llevan puestas. A través de la mirada del otro, las joyas otorgan a la persona que las lleva un significado elevado, transformando al individuo en algo sobre-individual. También las obras de arte tienen para Simmel la función de atraer, emanando un sentido elevado. Pero, para Simmel, la atracción de la obra de arte es diferente, ya que no tiene el objetivo de decorar a una persona, sino que atrae para hacer resaltar un "significado individual" inmanente en la obra (Simmel, 1992 [1908], p.

${ }^{2}$ Comentario en: https://www.youtube.com/watch?v=sSqU6vgs3Dc. Acceso: 10/7/2017. 
418). Simmel se refiere con "significado individual" a una especie de contenido singular que el artista ha sabido expresar ¿Pero con qué intención se expresa en la obra de arte ese significado individual? Yo creo que Simmel en la obra de arte no sólo ve una expresión individual del artista, sino a la vez una expresión colectiva, siendo así la función del arte la de atraer para constituir comunidades o identidades colectivas. El sentido individual que emana de la obra de arte (musical, escultural o visual) pasa a tener un sentido colectivo, en el momento en que la obra de arte es acogida y entendida por el público. Cuando el público aplaude su surgimiento, como hemos visto en el ejemplo del Badauê, no sólo se deja llevar por un estado sorpresivo, sino que a la vez pone en movimiento a un grupo de personas, que aplaudiendo, moviéndose o cantando, participan de esa expresión artística, transformándola en una forma de acción y de vida colectiva. Es en este sentido que la obra de arte funciona como un puente entre el artista y el público.

Mi tesis es, pues, que la sociología del arte de Simmel se basa en una búsqueda de expresiones culturales que surgen en el medio artístico, a través de las obras individuales de los artistas ${ }^{3}$. Para poder entender esta función que Simmel le otorga al arte y al artista como educador de colectividades, me gustaría seguir los argumentos de algunas de las publicaciones en las que Simmel se ha dedicado a diferentes géneros artísticos: a la música, a la escultura y a la pintura. Se trata de muchos escritos que Simmel fue publicando a lo largo de su vida en diversas revistas. Sabemos que al final de su vida él había planeado publicar un libro sobre teoría del arte, recopilando todos los textos que había escrito sobre el tema (cf. Kölbl, 1998, p. 9). En este texto, no voy a poder tratar todos sus escritos sobre el arte. Lo que voy a hacer es una selección de forma cronológica. Primero trataré un texto que Simmel escribió en 1880 sobre la música cuando tenía 22 años, pues creo que la música para él juega un papel central como expresión cultural de la humanidad. Después seguiré

\footnotetext{
3 Barbara Aulinger, que recientemente ha escrito un texto sobre la sociología del arte de Simmel, hace resaltar que como él no llegó a sistematizar su sociología del arte, el intérprete tiene la posibilidad de establecer una sistematización propia (Aulinger 2017). Aulinger diferencía tres campos en los que el arte toma significado en la obra de Simmel: a) en su método artístico de tratar las formas sociales, b) en su análisis de grandes artistas, c) y en su análisis de fenómenos estéticos (Aulinger, 2017, p. 100).
} 
con otro texto poco conocido que Simmel, de diez años más tarde, en 1890, y con la edad de 32 años, dedicado a un libro muy famoso en aquella época, un libro sobre Rembrandt de un autor anónimo. Será necesario exponer primero el contenido de ese libro, para poder entender mejor la recepción que hace Simmel. Trataré después, de forma muy escueta, la reflexión que realiza Simmel sobre la obra escultórica de Rodin, en textos escritos entre 1902 y 1909. Finalmente, veremos que Simmel al final de su vida, en el año 1916, volverá a tratar en un libro la figura de Rembrandt.

Si bien en todos estos textos, vemos que Simmel siempre busca en el arte una expresión cultural del pueblo, que se expresa a través del artista o a través de expresiones artísticas grupales, veremos también como a lo largo de su vida va cambiando de postura y de predilección por determinadas expresiones artísticas. En estos cambios de postura y pareceres se hace patente que Simmel va encontrando en las obras de arte medios diferentes para entrar en diálogo. La pregunta que me gustaría poder responder al final de este texto es si Simmel, en sus estudios sobre el arte, al defender ciertas corrientes artísticas, está también defendiendo ciertas formas de vida. Es conocido que Simmel es el sociólogo que más ha sabido percibir la diversidad de expresiones culturales y formas de vida de su época ¿Cuáles son los momentos en que descubrimos las formas de vida en las que él mismo se reconoce? Creo que en sus escritos sobre el arte, Simmel nos deja ver cuáles son las expresiones culturales con las que él mismo fue acomodando su identidad.

\section{La música como expresión colectiva del pueblo}

En un trabajo con el título "Estudios psicológicos y etnológicos sobre la música" ${ }^{4}$ encontramos que Simmel analiza la función del arte musical como una atracción, de forma parecida a la función de las joyas. Siguiendo a Darwin, hace resaltar que el cantar de los pájaros tiene el objetivo de atraer

\footnotetext{
${ }^{4}$ Se trata de un texto que Simmel escribió, en 1880, como doctorado en la disciplina de etnografia, pero que no fue admitido por la universidad. Es por eso que al final presentó como tesis doctoral otro texto sobre Kant, con el que había ganado un premio. El texto sobre la música fue publicado en una revista en el año 1882. En: Zeitschrift für Völkerpsychologie und Sprachwissenschaft. Hg. v. M. Lazarus u. H. Steinthal. 13. Bd. 3. Heft. Berlin: Ferd. Dümmler/Harrwitz \& Gossmann 1882. p. 261305.
} 
sexualmente. Y la misma función de atracción le adjudica Simmel a la música. Pero Simmel hace ver que la atracción sexual no es el único objetivo, sino que el canto y la música también son formas de expresar otro tipo de emociones y afectos. En este sentido la función de la música como obra de arte consiste en saber expresar una diversidad de emociones, desde emociones de rabia, hasta afectos amorosos o sentimientos religiosos. Si bien Simmel analiza sobre todo fenómenos musicales de autoría grupal, hay un momento en donde expone la idea de que determinadas personas con talentos especiales, que hoy llamamos artistas, tienen la capacidad de crear músicas y cantos que expresan emociones grupales de forma paradigmática. Esas melodias creadas por esas personas con especiales talentos se transforman entonces en cantos colectivos, en Volksliedern, en expresiones del pueblo y de la nación.

En este estudio sobre la música se ve claramente que, para Simmel, el sentido del arte es expresar emociones que caracterizan a un pueblo. Y aunque para él a lo largo de la evolución, se hayan ido creando cada vez más formas sofisticadas de lenguaje musical, instrumental y lingüístico, esta función social permanece. Simmel aclara, en un apartado, que no se trata de expresar un patriotismo, sino que más bien el artista sabe expresar de forma inconsciente lo que el pueblo siente, un sentimiento colectivo. De todas formas, muchos de los ejemplos que expone Simmel ilustran sentimientos colectivos ligados a las identidades nacionales. Hay así algunos comentarios sobre el carácter francés o italiano, que emanan de sus expresiones musicales. Simmel recorre a ejemplos de expresiones artísticas de todas partes del mundo, haciendo referencia sobre todo a estudios etnológicos. La sociología todavía no era su campo de trabajo, pero existían algunas referencias a la sociedad moderna, como veremos ahora.

Sabemos que veinte años después de este primer texto etnológico, en 1911 , en sus textos sobre la cultura de la modernidad, Simmel expuso su diagnóstico de que la tragedia del hombre moderno es la de no poder identificarse con los productos y expresiones culturales, con las objetivaciones de la cultura (Simmel, 1996 [1911]). El hombre moderno, de acuerdo con su diagnóstico, pierde cada vez más la identificación con las 
expresiones culturales, sean estas productos individuales o colectivos, transformándose la cultura en una entidad ajena. En este primer texto etnográfico, Simmel no le presta todavía atención especial a la música moderna y no hay ninguna referencia a la crisis de la modernidad y a la "tragedia de la cultura". Sólo en algún momento puntual encontramos cierta información sobre la expresión musical de su época, pero de forma muy escueta, cuando por ejemplo anota que "todavia hoy, cuando hay una obra musical que nos emociona, cantamos de forma inconsciente, o movemos por lo menos las manos o los pies siguiendo el ritmo" (Simmel, 2000 [1882], p. 68-69). En esta cita, vemos que Simmel percibe que todavía existe una capacidad en el hombre moderno de dejarse llevar por productos culturales como la música. Si bien, cabe aclarar que ese movimiento inconsciente de los pies y las manos parece un movimiento tímido, que pasa casi desapercibido, como un resto inconsciente que todavía ha quedado de tiempos lejanos. En contraste los bailes y cantos de los otros países que Simmel analiza en el texto y que recorren el mundo entero, desde Brasil y México hasta Persia, parecen todos ser conscientes, intensivos, emotivos y energéticos ${ }^{5}$.

Hay otras partes en el texto en donde Simmel trata de la música actual, como si esta estuviera acotada a algunos campos culturales que pertenecen al pasado: por ejemplo, en un apartado donde analiza las emociones religiosas y místicas. Aquí Simmel incluye una frase sobre un espacio en donde según él todavía persiste la fuerza de la música, el espacio religioso, donde aún en el púlpito sagrado y en la misa se practica un "tono cantarino". Otro resto de la fuerza musical lo encuentra en la música bélica y en las festividades militares, en donde todavía se usan instrumentos de viento y metal para poder resaltar el acto (cf. Simmel, 2000 [1882], p. 60).

En otro apartado del texto, Simmel traza una posible teoría evolutiva de la música, en donde la expresión musical a lo largo de la evolución va perdiendo cada vez más su carácter natural, su expresión de afectos, para ir

\footnotetext{
5 Simmel se refiere por ejemplo a las canciones de amor de los Maoris, en donde los refranes van acompañados de "sonidos guturales inarticulados", o cita un estudio sobre la etnografia de Brasil de Martius, en donde se describe que los Botocudos cuando tienen un deseo o una emoción muy intensa, realzan las palabras habladas en un cántico monótono (Simmel, 2000 [1882], p. 53).
} 
acercándose a su ideal como arte (cf. Simmel, 2000, p. 64). Eso no quiere decir, para él, que las emociones y los afectos desaparezcan, sino que los mismos no son más transportados de forma directa, sino a través de una mediación que funciona como una imagen que se refleja en el espejo de la belleza. El arte entonces se vuelve un mundo autónomo, un espejo en donde las emociones se exponen de forma abstracta, como si se tratara de un espejo de imágenes emotivas e ideales, que no obligan al espectador a cantar y a bailar, sino sólo a quedarse ensimismado por el ideal transportado. Tal vez dejándolo en un estado sorpresivo, con la boca abierta, como en el comentario al pie de la canción de Caetano en YouTube. Pero sigamos otros escritos de Simmel en donde no sólo la música, sino también la pintura y la escultura van a ser medios de expresión de emociones colectivas.

\section{Rembrandt como educador del pueblo: la obra de Julius Langbehn, el Rembrandt alemán}

En 1890, Georg Simmel escribió una pequeña reseña sobre el libro de un autor anónimo que ese mismo año fue publicado en una editorial alemana, la editorial de C. L. Hirschfeld. Se trata de un libro sobre la salvación de la cultura alemana a través de la mano de los artistas y en concreto a través de la mano y obra del artista holandés Rembrandt Harmenszoon van Rijn. El libro con el título "Rembrandt como educador. Por un alemán" viene cargado de un análisis crítico de la modernidad, que según el autor anónimo está destruyendo cada vez más el carácter individual, la voluntad artística propia del pueblo ario. Los argumentos en contra de la modernidad son conocidos: el materialismo, el liberalismo, el cosmopolitismo, la ciudad y el uniformismo son algunos de los principales enemigos. Las razones para dejarse ayudar por la obra de Rembrandt, que el autor anónimo propone, eran menos conocidas por aquel tiempo. El pintor Rembrandt, que murió en la miseria, lleno de deudas y refugiado en un barrio judío, había empezado a ser objeto de culto desde la publicación del libro de Eduard Kolloff, Rembrandts Leben und Werke [La vida y obra de Rembrandt (1854). Con el libro del autor anónimo Rembrandt pasó a tener una gran popularidad en la población alemana. Nada más aparecer se 
vendieron tantos ejemplares, que al poco tiempo surgió otra edición, surgiendo en el tiempo de dos años un total de cuarenta ediciones. Debido al interés que causó el libro, el autor anónimo se dio a conocer. Se trataba de Julius Langbehn, un historiador del arte de 39 años, que todavía no era conocido. En seguida se le puso el mote de Rembrandtdeutsche: el Rembrandt alemán. Un mote que él mismo utilizaba. Me parece importante estudiar este libro y también la figura de Langbehn, para poder entender mejor la postura que va a tomar Simmel en sus escritos sobre el arte. Yo creo que el libro de Langbehn le sirve a Simmel para reaccionar por un lado a una postura nacionalista que estaba surgiendo ya en aquella época y que con el Nacionalsocialismo tendrá su culminación catastrófica. Pero, como veremos más adelante la primera reacción que tiene Simmel, ante esta corriente nacionalista, cambiará después de 20 años de tal forma que uno casi va a tener la sensación de que Simmel, al final de su vida, también busca en la figura de Rembrandt una expresión artística a seguir como modelo de la identidad colectiva alemana. Por eso, prestemos atención primero a la vida y obra de Langbehn.

En la época que Julius Langbehn escribió su libro sobre Rembrandt, se encontraba en la ciudad de Dresde. El título del libro hace referencia a la tercera parte de Consideraciones intempestivas de Nietzsche con el título "Schopenhauer como educador"6. Se trata de un libro en donde Nietzsche critica la situación actual de la cultura alemana y apuesta por cambiar su rumbo. No es por casualidad que Langbehn tome este título de Nietzsche, ya que su objetivo era seguir el camino que plantea este autor de renovación de la cultura alemana. Nietzsche se encontraba en esa época internado en una clínica de la ciudad de Jena a cargo del médico Otto Binswanger ${ }^{7}$. Langbehn tenía planeado encontrarse con Nietzsche para poder sacarlo de su enfermedad y juntos poder renovar la cultura alemana. Es por eso que estaba en comunicación con la hermana de Nietzsche y esperaba en Dresde poder realizar su plan, consiguiendo varios encuentros con Nietzsche que

\footnotetext{
6 Consideraciones intempestivas es una recopilación de cuatro ensayos que Nietzsche publicó entre 1873 y 1876: "David Strauss, el confesor y el escritor", "Sobre la utilidad y el perjuicio de la historia para la vida", "Schopenhauer como educador" y "Richard Wagner en Bayreuth".

7 Nietzsche había sido llevado primeramente en enero de 1889 a un sanatorio en Basilea. Pocos días después la madre del filósofo, Franziska Oehler Nietzsche, lo trasladó al hospital psiquiátrico de Jena.
} 
tienen lugar en la clínica. Es justo en esa época de espera, entre el año 1889 y 1890, que Langbehn escribe el libro sobre "Rembrandt como educador". En el año 1891 Langbehn tuvo que dejar Dresde sin llegar a conseguir su objetivo de poder curar a Nietzsche. Langbehn había sido acusado de escribir un libro con textos pornográficos, que también había escrito en esa época de espera. Se trata de un libro con el título: "40 canciones de un alemán" (40 Lieder von einem Deutschen), el cual esta vez no publicó de forma anónima; y que no agradó tanto como el otro, obligándole incluso a dejar Alemania para poder escapar del juicio que se le estaba realizando. El contenido pornográfico del libro sobre 40 canciones es difícil de encontrar. Se trata de canciones dedicadas al amor. Es por eso que la primera frase del libro dice: "Quien ama, canta solo por su amor" (Wer liebt, singt nur von seiner Liebe). En el libro se encuentran también canciones dedicadas a temas religiosos y otras al pueblo alemán, como por ejemplo la canción "Deutsche Not" [ Angustia alemana]:

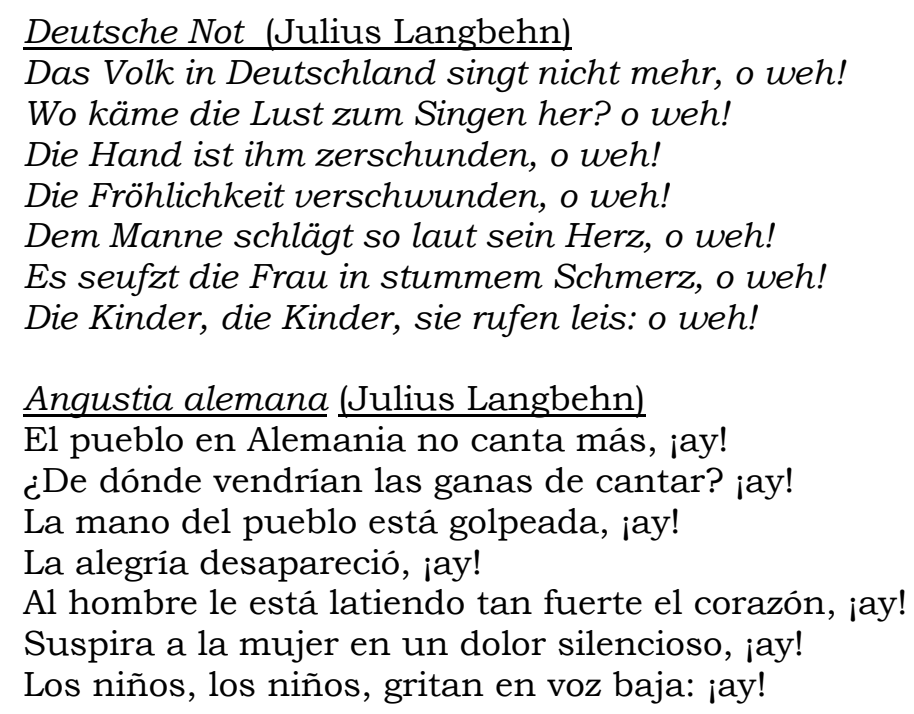

Esta canción nos da a entender cuál era para Langbehn el sentido del libro de las canciones alemanas, es decir, llevar al pueblo alemán en decadencia y en estado de angustia a amar sus propias expresiones culturales y religiosas; y a partir de ahí a cantar, pues, como dice, en la primera frase que guía el libro, solamente se canta lo que se ama.

El libro de las canciones sigue pues la misma intención pedagógica que había llevado a Langbehn a escribir el libro sobre Rembrandt: despertar 
en el pueblo alemán el amor por la expresión cultural alemana. También al comienzo del libro, sobre Rembrandt, expone que la cultura alemana se encuentra en una situación de decadencia. En el caso de la ciencia, debido a la especialización y, en el caso de la literatura y el arte, debido a que no existen artistas individuales que sean capaces de dar voz al pueblo. Los artistas, en su especialización y profesionalización, se han apartado del pueblo y no sirven más como puentes entre ellos y el público. Langbehn se queja también de que no existen músicos, solo musicantes; y crítica, sobre todo, la actitud de mirar y copiar lo que se hace en África, como una actitud que hace patente el alejamiento cada vez mayor de los artistas de su pueblo cercano. Langbehn Además, no hace referencia concreta a las corrientes artísticas que se fijan en África, pero sabemos que en aquella época no solo Paul Gauguin (1848-1903), sino otros artistas europeos tenían la mirada puesta en el viaje para renovarse artísticamente y así conseguir liberarse del estilo de las academias. Curiosamente, quince años después de la publicación del libro sobre Rembrandt, en 1905, en la misma ciudad de Dresde, se formará el grupo artístico Die Brücke, que realmente tomará como modelo el arte de África y Oceanía. Cabe destacar, que se trataba de grupo de artistas que al igual que Langbehn se guiaba por la obra de Nietzsche. Se dice que el nombre del grupo, Die Brücke (El Puente), viene de la frase de Así habló Zaratustra: "Vosotros solo sois puentes: qque se haga posible que de vosotros surja lo elevado!" (Nietzsche, 1999, p. 350) ${ }^{8}$, representando una clara apelación a los artistas para tomar en serio su tarea de mediadores, de puente entre el pueblo y un ideal elevado. El grupo de artistas de Dresden comprendió este mensaje y transformó su arte en un medio publicitario de una nueva forma de vida, siguiendo como modelo el arte primitivo, como también los bailes y rituales de una vida cercana a lo natural.

A diferencia de los artistas de Die Brücke la intención de Langbehn era llevar a los alemanes no a un Ideal que se creía encontrar en Oceanía o en África, sino por el contrario, a un Ideal típico y original del pueblo germano, pero que para él se había dejado olvidado. Mientras Schiller y Goethe, con los que Langbehn dialogaba, proponen una educación estética para toda la

8 Sobre el concepto de puente (Brücke) en Nietzsche ver Joisten, 1994, p. 91-98. 
humanidad, este último insiste en su libro, que no se trata de una educación para todos, sino para un pueblo que debe encontrarse a sí mismo. Para guiarse por este buen camino propone seguir ideales en la historia, héroes artísticos. Pero en vez de proponer un artista alemán, como tal vez esperaría el lector, propone a Rembrandt como héroe artístico y guía espiritual de los alemanes. Rembrandt es para Langbehn "el artista más alemán de todos los artistas alemanes" (Langbehn, 1922, p. 55). Rembrandt es declarado prototipo y guía que los alemanes tienen que tomar como modelo de vida, para poder llegar a encontrarse a sí mismos. Para Langbehn, lo que hace de Rembrandt un prototipo es su individualidad, su carácter excéntrico y una personalidad que se niega a ser atrapado en casillas establecidas. Es un artista que juega entre las polaridades, entre lo claro y lo oscuro. Un artista que busca individualidad y originalidad. El modelo a seguir no es entonces tanto la forma de pintar de Rembrandt, sino mas bien su personalidad, su actitud y su deseo de ser diferente. Si bien Rembrandt es el pintor elegido, Langbehn ofrece un panorama variado y caótico de todos los campos posibles en donde una cultura individual alemana puede tomar forma. Sobre el estilo pictórico de Rembrandt no se encuentran casi comentarios. Veamos como reacciona Simmel ante este libro y al espíritu renovador de Langbehn.

\section{El ataque de Simmel a Langbehn}

En su reseña sobre el libro de Langbehn Simmel adopta un estilo irónico, casi sarcástico, para comentar el mérito del libro (Simmel, 2009 [1890]) ${ }^{9}$. Por un lado, le da la razón a Langbehn en algunos puntos, haciendo hincapié en la necesidad de expresiones culturales nuevas que sepan articular los sentimientos de una época. Por otro, se burla de sus propósitos haciendo ver que el alemán anónimo es contradictorio ¿Como quiere salvar la cultura alemana de su decadencia a través de un individuo modelo como Rembrandt, un modelo que proviene de Holanda y no de Alemania? ¿Y, además, qué significa querer seguir a un modelo?, ¿Eso no lleva justamente a estar condenado a una continua imitación y a no seguir el

\footnotetext{
$9 \mathrm{El}$ texto de Simmel sobre el libro de Langbehn aparece el 1 de junio de 1890 en el periódico Berliner Vossische Zeitung.
} 
camino individual de la auto-identidad? Simmel expone que en realidad Langbehn podría haber elegido otro artista, un artista alemán, a Durero o a Beethoven, y que el libro podría haber sido el mismo, pues su verdadera intención es utilizar a Rembrandt para hacer propaganda sobre todo acerca de lo que él mismo cree que ha de conservarse del espíritu nacional alemán (cf. Simmel, 2009 [1890], p. 43). Simmel no solo hace ver esta contradicción del autor anónimo, sino que también expone su crítica al carácter conservador de la postura de Langbehn. En contra de las críticas que hace este último a la modernidad, a la ciencia y a la tecnología, Simmel hace ver que justamente en las novedades tecnológicas puede verse surgir un nuevo espíritu alemán; un espíritu innovador, en contra del espíritu conservador de Langbehn, que se apoye en los regionalismos y en el folclore. Además, ironizando el carácter patético de ese autor, Simmel destaca la nueva poesía y mitologia que se inspira en los descubrimientos científicos: en el notable alcance de lo descubierto en las ciencias naturales y en las extraordinarias invenciones como el telescopio y el microscopio... (Simmel, 2009 [1890], p. 31). Simmel ve surgir en tales novedades una nueva cultura y opina que de aquí surge también una nueva poesía y un nuevo arte, anticipándose así a la aparición del manifiesto futurista de 1909. Pero Simmel no defiende solo una poesía y un arte tecnológico del futuro, pues explica que todo fenómeno de la actualidad contiene la potencialidad de volverse poético, apoyando así un pluralismo artístico y una pluralidad de formas de vida, en donde incluso la postura de Langbehn tiene razón de ser. Vemos aquí una actitud pluralista, que ha sido característica de todos los escritos de Simmel, en siempre permitir a los contrarios una razón de ser, lo que varias veces le ha llevado a ser criticado de relativista.

En la reseña de Simmel vemos claramente como, de una forma irónica, ataca la posición nacionalista y conservadora de Langbehn; haciendo ver con su misma intención de renovación de la cultura alemana, que esta puede a través de la ciencia encontrar un nuevo rumbo, un nuevo espíritu, una nueva expresión poética y artística. Si bien del texto de Simmel emana un claro optimismo con relación a la renovación de la cultura, como si esta se diera automáticamente, hay un apartado en el que vuelve a la fuerza de la 
música y opina que, en la actualidad, la música es el género artístico que tiene más fuerza de radiación. El diagnóstico es que todas las artes visuales están muy apegadas a representaciones de la realidad y que la música, como “el medio artístico más abstracto que existe” (Simmel, 2009 [1890], p. 33), puede ser la fuerza integradora capaz de ofrecer una expresión artística colectiva para toda una época. Simmel no habla aquí de una fuerza colectiva para Alemania, o para la Nación o para Europa. Él habla de una expresión artística capaz de expresar la generalidad de las emociones de todos los hombres, como si viese en la música una fuerza expresiva capaz de integrar una colectividad mundial, más allá de las diferencias culturales o nacionales.

Pasemos ahora a otro medio artístico, a la escultura, y a otra manera que encuentra Simmel de, a través del arte, encontrar otra promesa de ser.

\section{Simmel y Rodin}

Los artículos que Simmel le dedica al escultor Auguste Rodin (18401917) son muchos y con algunas variaciones. Seguramente descubre su obra escultórica en la Exposición Internacional de París en 1900. Con seguridad se sabe que, en 1902, visita una exposición de esculturas de Rodin en Praga y escribe ese mismo año su primer texto: "La plástica de Rodin y la dirección espiritual de la actualidad" (Simmel, 1995 [1902]) ${ }^{10}$. A este artículo le seguirán otros y también varias conferencias. En este periodo de su vida, Simmel ve materializarse en la obra de Rodin la forma de vida de la modernidad; una modernidad en continuo movimiento, fluyente y abierta a la pluralidad de estilos. Un año antes ya habia escrito sobre la escultura, en un artículo con el título "Estética del peso" (Simmel, 1995 [1901]) ${ }^{11}$, en donde explicaba que la escultura es un medio que justamente por sus materiales duros, sirve de ejemplo paradigmático para ver cómo el sujeto moderno busca expresarse superando todo tipo resistencia. Sobre todo, el mármol es para Simmel el material que más ofrece resistencia a ser tallado. El artista tiene que mostrar su "voluntad artística" para poder dar

\footnotetext{
$10 \mathrm{El}$ artículo aparece el 29 de septiembre en el periódico Berliner Tageblatt con el título: "Rodins Plastik und die Geistesrichtung der Gegenwart".

${ }_{11}$ Este primer texto sobre escultura aparece también en el Berliner Tageblatt, el 10 de Junio de 1901.
} 
forma a este material ${ }^{12}$. Simmel alaba a Rodin en su capacidad en trabajar la piedra y sacar de los bloques del mármol formas y figuras dinámicas, cargadas de movimiento. Hace referencia, por un lado, a los bloques de mármol que Rodin deja aparentemente sin trabajar y desde donde surgen cuerpos humanos que al parecer están liberándose del bloque. Otras esculturas que Simmel trata como innovaciones del artista son sus pequeñas figuras en movimiento, que según cuentan surgen de la costumbre de Rodin de pedir a sus modelos de no quedarse quietos, y así capturar las vibraciones de los cuerpos. En estos trabajos de Rodin, Simmel ve de forma paradigmática la expresión de una modernidad que se guía por un continuo cambio. Se trata de un cambio y un movimiento continuo, que, como Simmel expone, en otro texto dedicado a Rodin, está abierto a diferentes caminos: "caminos sin objetivos concretos y objetivos sin caminos" (Simmel, 1996, p. 330). El valor de las esculturas de Rodin se esconde, para Simmel, en esa capacidad de expresar la identidad colectiva del sujeto moderno, un sujeto en continuo cambio y vibración de los sentidos. Simmel no solo estudia la obra de Rodin, sino que también se propone seguir una filosofia equivalente a su escultura. Como si la obra de Rodin no sólo sirviese de puente expresivo entre la intención del artista y la identidad colectiva del público moderno, sino también entre el arte y su filosofia.

Hay una anécdota curiosa, después de una conferencia que da Simmel en Viena en el año 1911, con el título "Significado histórico-cultural de Rodin” (2000 [1911]). Una de las personas que estaba entre el público de la conferencia era el comunista, político revolucionario Leon Trotzki, quien al poco tiempo escribió una reseña sobre la impresión que le causó el discurso de Simmel. En esta reseña se deduce a las claras que Trotzki no concuerda con la idea de declarar esta vibración continua como la forma de vida paradigmática de la modernidad. La modernidad que defiende Trotzki es otra completamente diferente y es por eso que se refiere de forma burlona al nuevo arte y a la nueva alma que proclama Simmel:

Sobre el arte nuevo y la 'nueva alma' habló recientemente con nosotros en Viena el profesor de Berlín Georg Simmel, en una

12 Simmel aparentemente no sabía que Rodin no trabajaba el mármol directamente y que sus esculturas las hacia en arcilla para después ser traspasadas al mármol. 
brillante conferencia sobre Rodin. La 'nueva alma' está permanentemente en movimiento, y este movimiento no tiene objetivos, ni dogmas. (...) Esa 'nueva alma' combina todos los opuestos: su 'no' es a la vez un 'si', cree y no cree a la vez, ama objetivos sin caminos, como también caminos si objetivo alguno (Trotzki, 2000 [1911], p. 218).

Trotzki caracteriza a esta nueva alma moderna como la típica postura del burgués urbano, viendo detrás del "alma" en continuo movimiento, al sujeto consumista, que no produce nada y sólo busca el goce continuo. La nueva alma de Rodin y Simmel es para Trotzki el alma del "burgués consumidor y gozador" (Trotzki, 2000 [1911], p. 220), dispuesto a consumir todo lo que se le ofrezca. Trotzki critica esta ideología burguesa y declara que "la nueva alma" no se encuentra en el consumista insaciable, sino que en la clase trabajadora; una clase que se mueve con un objetivo concreto, el comunismo, y un camino concreto, la Revolución.

En este comentario de Trotzki vemos como el arte pasa a ser un campo de batalla de las ideologías. La defensa pública de Simmel por la obra de Rodin es vista como la defensa por un estilo de vida burgués y consumista. Trotzki, por el contrario, busca un arte en donde se exprese la lucha del proletariado y la necesidad de la revolución. Más tarde, en 1923, Trotzki publicará su libro Literatura y Revolución, en donde propone que las artes han de servir para educar a un nuevo hombre. A través de las artes, proclama, surgirá un "hombre más fuerte, más inteligente y fino; su cuerpo se hará más armónico, sus movimientos más rítmicos y su voz más musical. (...) El hombre común se elevará hacia el nivel de Aristóteles, Goethe y Marx. Y sobre esta cordillera se elevarán nuevos picos" (Trotzki, 1994 [1923], p. 252). En Trotzki también encontramos la promesa del arte de servir de puente para lo más elevado.

\section{Otra vez Rembrandt}

Años más tarde, en 1916, Simmel volverá a tratar a la figura de Rembrandt, dedicándole un libro de doscientas páginas. En esta publicación parece como si muchos de los argumentos que él mismo había criticado en Langbehn, hayan sido olvidados por completo. Por un lado, ve Simmel en Rembrandt la capacidad, como en Rodin, de expresar el movimiento y el 
pulso variable de la vida. Ese movimiento se expresa, sobre todo, para Simmel, en los grabados del artista; con pocos trazos, cargados de dinamismo; o en los retratos, en donde toda una vida, pasado y futuro del retratado, parece condensarse en un momento. Pero Simmel alaba también en la obra de Rembrandt la emanación de una expresión cultural diferente del arte clásico y parecida al arte germánico, estableciendo paralelismos, por ejemplo, entre la melancolía de Durero y las pinturas holandesas; y resaltando que el arte de Rembrandt y el arte germánico buscan la individualidad. Simmel no cita en ningún momento a Langbehn y no sigue tampoco los mismos contenidos sobre la cultura alemana, pero en algunas partes del libro, en donde trata del arte germano, vemos a Simmel acercarse a la postura de Langbehn, de querer ver en Rembrandt una personalidad individual en donde se expresa una voluntad artística semejante a la del pueblo germano ¿A qué se debe este repentino cambio? Sólo podemos conjeturar que Simmel busca, como judío alemán asimilado, darse a conocer y comprenderse en una identidad nacional germánica, siguiendo entonces un discurso nacionalista ${ }^{13}$. Tal vez fuese una estrategia de hacerse reconocer en una sociedad en donde el antisemitismo se hacía cada vez más patente. Hannah Arendt ha reflexionado en su exilio sobre el camino de la élite judía europea, predestinada a quererse integrar en cada nueva nación que le acogía. En un texto escrito en el exilio titulado "Nosotros los exiliados" Hannah Arendt (1986 [1943]) ve con claridad que el camino de la integración de los judíos en Europa ha sido falso y sin salida. De forma paradigmática cuenta la vida del judío Cohn de Berlín, que en Alemania era el más patriótico de todos, un "superpatriótico" (Arendt 1986: 16), hasta que se ve obligado a exiliarse en Praga. En su nueva patria trata de ser un patriota checo, hasta que tiene nuevamente que huir y crear un nuevo hogar en Viena acomodándose nuevamente a un nacionalismo alemán-austriaco. Pero la llegada de los nazis vuelve a obligar a Cohn a dejar Viena, buscando acogida en París, en donde también creerá haber encontrado una nueva patria. Hannah Arendt expone este ejemplo del personaje Cohn para hacer

\footnotetext{
13 Bernard Sussen apunta que hay una gran semejanza entre el libro de Langbehn y el Sionismo de Buber (Susser, 1977, p. 81). Asher D. Biemann (2009) ha investigado la intención renovadora de la cultura, la idea del Renacimiento, en el judaísmo moderno.
} 
ver la imposibilidad de la integración de los judíos y apela por la identidad del "paria consciente", una figura contraria al personaje Cohn, el parvenue, que huye constantemente de su verdadera identidad, la identidad de estar excluido.

Tal vez Simmel eligió al final de su vida la obra de Rembrandt para reflejarse en ese espejo, tratando de mirarse en la identidad germana, pero con la conciencia de que Rembrandt en realidad no era alemán, sino por excelencia un artista excluido. Lo que podemos constatar es que en el libro sobre Rembrandt, Simmel lleva a la práctica lo que él veía en el arte: un medio de creación de entidades colectivas y de formas de vida. Tal vez le podamos dar otra lectura a este último libro, investigando los momentos en que Simmel busca la expresión de la figura de un alma extranjera, de un paria, como diría Hannah Arendt. Y si bien Simmel no se refiere a la biografia de Rembrandt, como artista expatriado, hay un momento al final del primer capítulo en donde propone la figura del extranjero para poder nombrar la ley formal (Formgesetz) que caracteriza la obra de Rembrandt (Simmel, 1919 [1916], p. 66-67). El extranjero, que, como veremos, tiene para Simmel como función permanecer variable, en un continuo movimiento entre permanencia y partida.

\section{La promesa del arte}

Muchos de los intérpretes de Simmel comentan que es extraño que en su reseña sobre el libro de Langbehn no aparezca ninguna observación sobre el antisemitismo del anónimo alemán. Simmel pertenece a una generación de judios alemanes integrados en la sociedad urbana y moderna, pero que continuamente tienen que padecer la exclusión que se les seguía haciendo, sean convertidos, asimilados o no, en todas las capas de la sociedad. Simmel realmente no hace referencia a los comentarios de Langbehn sobre la cultura judía, si bien la reseña aparece en un periódico que estaba en manos de un director judío ${ }^{14}$. Habría que estudiar las referencias que hace Langbehn a la cultura judía. Así veríamos que los comentarios antisemitas no aparecen en las primeras ediciones. Hay un capítulo dedicado a los judíos, "El judaísmos

14 El Vossische Zeitung surgió en 1704 en y fue comprado en 1913 por la familia judía Ullstein. 
noble e innoble" (Langbehn 1922, p. 361-363), donde Langbehn plantea una postura parecida a la de Hannah Arendt, criticando la búsqueda de integración y asimilación de los judíos europeos, y resaltando que la cultura judía, así como la alemana, solamente aporta algo de valor a la humanidad, si sabe hacer valer sus aportes culturales propios, realzando por ejemplo el valor de Baruch Spinoza. Seguramente esta apelación de Langbehn a los judios de volver a sus orígenes, no debe haber sido del agrado de Simmel y es por eso que puede no haber hecho ninguna referencia a este capitulo.

Vilém Flusser escribe, en su autobiografia, que la identidad de un joven de familia de intelectuales judíos, nacido y criado en Praga, era una identidad urbana e internacionalista, que se burlaba de las diferencias nacionales (Flusser, 1999). Flusser comenta, que no se trataba de un internacionalismo socialista, que espera la superación de las diferencias nacionales a través de la llegada de la Revolución. La identidad internacionalista para Flusser era una identidad urbana, característica de la ciudad de Praga, pero que con la llegada de los nacionalismos y sobre todo del nacional-socialismo alemán, comenzó a resquebrajarse. En esa época, Flusser ve llegar otras alternativas para los judíos asimilados, como por ejemplo el Sionismo, que en un comienzo fue tratado con escepticismo, pues era visto como reacción al antisemitismo en general y al nacional-socialismo en particular (Flusser, 1999, p. 17). El Sionismo era considerado diametralmente opuesto a lo que realmente se consideraba el rol del judaísmo en Praga: "ser un puente entre los pueblos" (Flusser, 1999, p. 17). A través del Marxismo, como camino científico de superación de las diferencias sociales, se esperaba la llegada de una "síntesis cultural", que ya se veía ponerse en práctica en la vida multicultural de Praga (Flusser, 1999, p. 18). Flusser describe su identificación con el marxismo como un marxismo falso, que no surge del odio al capitalismo, sino más bien de una enajenación del intelectual judío burgués, que no se podía identificar con el judaísmo y menos con el cristianismo, quedando solo la identificación con el marxismo como una lucha contra el nacionalismo a favor de un internacionalismo (Flusser, 1999, p. 20). 
En el momento que Flusser cuenta que deja Praga, da comienzo la vida sin fundamento (Bodenlosigkeit), que no sólo supone una pérdida de las identidades que antes lo constituian, sino que también supone una liberación de todo tipo de atadura, exponiéndose el sujeto ante un horizonte abierto, sin final. En este estado de Bodenlosigkeit es que Flusser describe una postura que yo creo que fue también característica de Simmel, la postura de no identificarse con ninguna identidad y de poder entonces entusiasmarse con practicar una "observación lúdica" (spielerisches Zusehen). Esa postura es descrita por Flusser también como "Gleichwerten aller Werte" (igualdad de todos los valores), en que toda postura es valorada, pues por un lado todo "le da igual" y por otro "todo es igual". Ya no es más el individuo enajenado, que no se puede identificar con ningún objeto de la cultura, con ninguna identidad, sino que se trata del sujeto distanciado y observador, dispuesto a observar con curiosidad todo lo que sucede: "Todo le era indiferente, o también igual, y es por eso que todo le despertaba el mismo interés" (Flusser, 1999, p. 35).

Ese estado de distanciamiento, pero a la vez de interés constante ante la variedad y proliferación de valores y discursos, es un estado que encontramos también en Simmel. Flusser lo ha reflexionado como un estado sin fundamento, sin suelo (Bodenlosigkeit), en donde se toma una postura de observación interesada, como un científico interesado por toda realidad que le rodea, pero también como un diablo que mira el escenario de luchas entre sistemas de pensamientos y formas de vida con un interés casi maligno. En Simmel encontramos una reflexión sobre esta forma de vida sin fundamento (Bodenlosigkeit) en su texto sobre "El extranjero" (Simmel, 1992 [764-771]). La figura del extranjero tiene la función de establecer un entendimiento entre los conflictos internos que se dan dentro de una sociedad. Justamente, ese distanciamiento, que tiene el extranjero, le permite poder escuchar las diferencias que han llevado a los conflictos y poder entonces, como un juez, establecer un acuerdo y un nuevo entendimiento. Esta es una de las funciones positivas que Simmel hace resaltar en la figura del extranjero: la de volverse un juez imparcial. 
Yo creo que Simmel le otorga también al arte esa misma función de establecer lazos de entendimiento. Cuando el arte es capaz de atraer, en su radio de acción, a una diversidad de personas que ante su aparición aplauden al unísono. Como si en ese momento de compartir una expresión artística, existiera un entendimiento grupal incondicional. Pero ese entendimiento solamente dura el tiempo en que la expresión artística es aplaudida, otorgando una entidad colectiva con la que todos se identifican aplaudiendo, cantando o moviendo los pies, como en el Badauê. En el momento en que la expresión artística concluye, vuelven las diferencias y la identificación grupal desaparece.

Chico Buarque ha tratado en su canción La Banda justamente esta decepción de ver que el lazo grupal que surge a través de compartir una expresión cultural desaparece inmediatamente en el momento en que la banda deja de tocar. Chico Buarque canta primero la situación alegre de cuando la banda pasa por la ciudad y todos los habitantes olvidan sus diferencias y sufrimientos para dejarse llevar por la música. Cuando la banda desaparece de la calle, la gente retorna a sus sufrimientos y a sus lugares respectivos. Entonces el artista expone su decepción, que el efecto del arte haya desaparecido inmediatamente en el momento que la banda para de tocar. La utopía de un entendimiento entre las personas a través de la música se ve desvanecer, al poco tiempo de pasar la banda cantando canciones de amor.

\section{A Banda (Chico Buarque)}

Estava à toa na vida O meu amor me chamou Pra ver a banda passar Cantando coisas de amor

A minha gente sofrida Despediu-se da dor Pra ver a banda passar Cantando coisas de amor

(...)

Mas para meu desencanto O que era doce acabou Tudo tomou seu lugar Depois que a banda passou 
También en los escritos de Simmel encontramos esta promesa del arte que expone Chico Buarque en A Banda. Como he querido mostrar, Simmel a lo largo de su vida vio en diferentes corrientes artísticas la posibilidad de a través del arte dar expresión y forma a identidades colectivas. Encontramos a un joven Simmel optimista, que cree en el arte como instrumento de renovación de la cultura y apoya, en contra de Langbehn, una renovación cultural siguiendo el pulso del tiempo, de la técnica y la ciencia. Más adelante reflexionará Simmel no sólo sobre los aspectos positivos de la modernidad, sino también sobre sus consecuencias negativas. Y en una especie de postura ambivalente, abierta a los continuos cambios, a la pluralidad (de los estilos y modas) y al movimiento continuo de la modernidad, defenderá la escultura vibrante de Rodin, como si el arte escultórico pudiese de forma concisa expresar la energía positiva del sujeto moderno, un sujeto abierto a todo posible cambio. Al final de su vida, Simmel retorna a un arte apaciguador de los opuestos, a un arte que en el claroscuro de las pinturas de Rembrandt parece prometer un entendimiento entre tendencias aparentemente contrarias. Si bien Simmel no reflexiona sobre la biografia de Rembrandt, pues se propone centrarse solamente en la obra artística, podemos ver que el contenido filosófico que Simmel resalta en la obra de arte de Rembrandt es un contenido que emana también de la forma de vida que siguió el artista. Rembrandt representa una figura parecida a la figura del extranjero tratado por Simmel. Una figura que permanece en un juego entre cercanía y distanciamiento, entre llegada y partida, entre la oscuridad y lo iluminado, para poder así establecer un puente entre las emociones variables del ser humano. El arte como puente, como dice Nietzsche. Un puente, que como canta Chico Buarque, suele dejar de funcionar, cuando la banda deja de cantar. Un puente también que puede generar sentimientos colectivos en diferentes direcciones, prestándose a cualquier tipo de concepciones: ya sea la ideología nacionalista y excluyente de Langbehn o la concepción del mundo revolucionaria de Trotzki, en donde el arte sigue el objetivo de construir una sociedad futura igualitaria, o la concepción individualista ("burguesa") de ver en el mismo un espejo de la subjetividad cambiante, la subjetividad colectiva del sujeto 
moderno. El arte se presta así a diferentes identidades colectivas y los artistas parecen tener la función, quieran o no, de servir de puentes hacia esas colectividades. Simmel, a su vez, a través de sus escritos parece querer también cumplir esta función de puente, dejándose inspirar por las obras de arte. Y si bien sus predilecciones artísticas nos hacen ver que Simmel a lo largo de su vida va cambiando de parecer, hay una búsqueda que permanece constante: la de encontrar en el arte la superación de las diferencias contingentes, para poder unir a todos los hombres sin excepción en una colectividad hermanada.

\section{Referencias}

ARENDT, Hannah. Wir Flüchlinge (1943). In: Zur Zeit. Politische Essays. Berlin: Rotbug, 1986.

AULINGER, Barbara. Georg Simmel. In: Steuerwald, Christian. Klassiker der Soziologie der Künste. Wiesbaden: Springer, 2017.

D. BIEMANN, von Asher. Inventing New Beginnings: On the Idea of Renaissance in Modern Judaism. Standford: Stanford University Press, 2009.

FLUSSER, Vilém. Bodenlos: Eine philosophische Autobiographie. München: Fischer, 1999.

FRISBY, David (ed.), Georg Simmel in Wien. Texte und Kontexte aus dem Wien der Jahrhundertwende. Vienna: Universitätsverlag, 2000.

JOISTEN, Karen. Die Überwindung der Anthropozentrizität durch Friedrich Nietzsche. Würzburg: Königshausen \& Neumann, 1994.

KÖLBL, Alois. Das Leben der Form. Georg Simmels kunstphilosophischer Versuch über Rembrandt. Wien: Bählau, 1998.

LANGBEHN, Julius. Rembrandt als Erzieher. 50. Auflage. Leipzig: Hirschfeld, 1922.

LIEBESCHÜTZ, Hans. Von Georg Simmel zu Franz Rosenzweig. Studien zum Jüdischen Denken im deutschen Kulturbereich. Tübingen: Mohr, 1970.

NIETZSCHE, Friedrich: Also sprach Zarathustra. Bd. 4., München: Deutsche Taschenbuchverlag, 1999.

SIMMEL, Georg. Rembrandt. Ein kunstphilosophischer Versuch. Leipzig: Kurt Wolff, Zweite Auflage, 1919. 
Soziologie. Untersuchungen über die Formen der Vergesellschaftungen. Gesamtausgabe Band 11. Frankfurt am Main: Suhrkamp, 1992.

Ästhetik der Schwere [1901]. In: Simmel, Georg. Aufsätze und Abhandlungen 1901-1908. Gesamtausgabe Band 7. Frankfurt am Main: Suhrkamp, 1995.

. Rodins Plastik und die Geistesrichtung der Gegenwart [1901]. In: Simmel, Georg. Aufsätze und Abhandlungen 1901-1908. Gesamtausgabe Band 7. Frankfurt am Main: Suhrkamp, 1995.

Der Begriff und die Tragödie der Kultur [1911]. In: Simmel, Georg. Hauptprobleme der Philosophie / Philosophische Kultur. Gesamtausgabe Band 14. Frankfurt am Main: Suhrkamp, 1996.

Rodin (mit einer Vorbemerkung über Meunier) [1911]. In: Simmel, Georg. Hauptprobleme der Philosophie / Philosophische Kultur. Gesamtausgabe Band 14. Frankfurt am Main: Suhrkamp, 1996.

. Die kulturgeschichtliche Bedeutung Rodins. In: FRISBY, David (ed.), Georg Simmel in Wien. Texte und Kontexte aus dem Wien der Jahrhundertwende. Vienna: Universitätsverlag, 2000.

. Rembrandt als Erzieher. In: Simmel, Georg. Soziologische Ästhetik. Wiesbaden: Verlag für Sozialwissenschaften, 2009.

. Psychologische und ethnologische Studien über Musik [1882]. In:

Simmel, Georg. Abhandlungen 1882-1884. Rezensionen 1883-1901. Gesamtausgabe Band 1, Frankfurt am Main: Suhrkamp, 2000.

SUSSER, Bernard. Ideological Multivalence: Martin Buber and the German Volkish Tradition. Political Theory. v. 5, n. 1, 1977.

TROTZKI, Leo. Zwei Wiener Ausstellungen im Jahre 1911. In: David Frisby (Hg.), Georg Simmel in Wien. Texte und Kontexte aus dem Wien der Jahrhundertwende, Vienna: Universitätsverlag, 2000.

Literatur und Revolution. Essen: Arbeiterpresseverlag, 1994.

WAUSCHKUHN, Annette. Georg Simmels Rembrandt-Bild. Ein lebensphilosophischer Beitrag zur Rembrandtrezeption im 20. Jahrhundert. Worms: Wernersche Verlagsgesellschaft, 2002. 